\title{
ERA UMA VEZ... UMA HISTÓRIA DE ADOÇÃO: CONTRIBUIÇÕES PARA A CONSTRUÇÃO DE UMA CULTURA ADOTIVA NA ESCOLA
}

\author{
Gilmara Lupion Moreno ${ }^{1}$ \\ (D) https://orcid.org/0000-0002-4435-878X \\ Thainara Suleiman Campachi Antonio ${ }^{2}$ \\ (D) https://orcid.org/0000-0002-4630-2392
}

Resumo: $O$ artigo versou sobre a relevância da literatura no desenvolvimento infantil e do uso de histórias literárias para conversar sobre adoção com as crianças na escola. Objetivou-se apresentar livros infantis que tratam sobre o tema e suas contribuições para a construção da cultura da adoção. Trata-se de uma pesquisa qualitativa, do tipo bibliográfica e da análise de obras literárias que falam sobre adoção. Os resultados destacam a literatura como mediadora na formação das crianças, capaz de apresentar, de forma simples e lúdica, a adoção. Esperamos que os livros analisados possam contribuir com o trabalho docente na construção da cultura adotiva.

Palavras-chave: adoção; escola; literatura infantil; desenvolvimento infantil; trabalho docente.

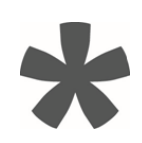

1 Mestrado em Programa de Mestrado em Educação pela Universidade Estadual de Londrina e doutorado em Programa de doutorado em educação pela Universidade de São Paulo - USP Atualmente é professor adjunto da Universidade Estadual de Londrina. Tem experiência na área de Educação, com ênfase em Educação Infantil, atuando principalmente nos seguintes temas: História e Legislação da Educação Infantil; Trabalho Pedagógico na Educação Infantil; Relação escola-família na educação infantil. E-mail: gilmaralupion@hotmail.com

${ }^{2}$ Graduada em Pedagogia pela Universidade Estadual de Londrina (UEL). E-mail: thainara06@gmail.com 


\section{ONCE UPON A TIME... A STORY ABOUT ADOPTION: CONTRIBUTIONS TO THE ESTABLISHMENT OF AN ADOPTION CULTURE AT SCHOOL}

Abstract: The article is about the relevance of literature in child development and the use of literary stories to talk about adoption with children at school. The objective was to present children's books that deal with the theme and their contributions to the construction of the culture of adoption. This is a qualitative research, of bibliographic type, and the analysis of literary works that talk about adoption. The results highlight literature as a mediator in the formation of children, capable of presenting adoption in a simple and playful way. We hope that the analyzed books can contribute with the teaching work in the construction of the adoptive culture.

Keywords: adoption; school; children's literature; child development; teaching work.

\section{ÉRASE UNA VEZ ... UNA HISTORIA DE ADOPCIÓN: CONTRIBUCIONES A LA CONSTRUCCIÓN DE UNA CULTURA ADOPTIVA EN LA ESCUELA}

Resumen: El artículo trata de la relevancia de la literatura en el desarrollo infantil y del uso de cuentos literarios para hablar de la adopción con los niños en la escuela. Su objetivo era presentar libros infantiles que trataran el tema y sus aportaciones a la construcción de la cultura de la adopción. Se trata de una investigación cualitativa, de tipo bibliográfico y de análisis de obras literarias que hablan de la adopción. Los resultados destacan la literatura como mediadora en la formación de los niños, capaz de presentar, de forma sencilla y lúdica, la adopción. Esperamos que los libros analizados puedan contribuir con la labor docente en la construcción de la cultura adoptiva.

Palabras clave: adopción; la escuela; literatura infantil; desarrollo infantil; trabajo docente. 


\section{Introdução}

A adoção no Brasil e no mundo passou por muitas mudanças e avanços, sendo um ato que acontece desde os primórdios, e está inserido na sociedade até hoje. Ela aparece em filmes, novelas, comerciais, livros etc., e no cotidiano, em meio aos abandonos, ao acolhimento das crianças e adolescentes em abrigos e às adoções que ocorrem nas Varas da Infância e Juventude. Dessa forma, entendemos a necessidade de quebrar mitos e barreiras ainda existentes sobre o assunto, pois a adoção permite que pais, crianças e adolescentes encontrem uma família na qual os laços de sangue não importam, mas sim o afeto.

Acredita-se que a escola possa ser um meio importante na construção de uma cultura na qual a adoção seja vista como uma via de parentalidade. Entretanto, para que isso aconteça, é preciso que os profissionais da educação estejam preparados para essa tarefa. Nos cursos de formação inicial e continuada, o conhecimento sobre adoção faz-se necessário, pois, muitas vezes, os professores não sabem como lidar com crianças e famílias constituídas por adoção. Mas como trabalhar a adoção com as crianças da Educação Infantil e dos Anos Iniciais do Ensino Fundamental? Uma das possibilidades são os livros infantis que tratam sobre o tema, uma vez que a literatura contribui na formação pessoal e social das crianças.

Sendo assim, 'Adoção e Literatura Infantil' foi o tema escolhido para o desenvolvimento deste estudo, pois acredita-se que, por meio da leitura, é possível desenvolver a cultura da adoção na escola, uma vez que as crianças apreciam a contação de histórias. Entretanto, faz-se necessário analisar as obras literárias que tratam sobre adoção, a fim de verificar a contribuição destas para a construção de uma cultura adotiva. Portanto, elegeu-se a questão-problema: os livros infantis que tratam sobre adoção contribuem para a construção de uma cultura adotiva?

De acordo com Vieira (2006), Moreno (2017) e Pantoja (2020) são muitos os livros infantis que abordam a adoção, sendo apresentada de diversas formas, tanto de forma primária quanto secundária. Os livros mostram a relação de famílias miscigenadas, de diferentes raças, etnias e gêneros, buscando, dessa forma, romper com estigmas e padrões preestabelecidos pela sociedade que idealizam uma família constituída por pai, mãe e filhos biológicos. 
A escola e a literatura podem se tornar o espaço para a criança refletir sobre sua condição pessoal; sua emancipação pode derivar de uma aliança entre esses dois sujeitos (ZILBERMAN, 1987). "Preservar as relações entre a literatura e a escola, ou o uso do livro em sala de aula, decorre do fato de que ambas compartilham um aspecto em comum: a natureza formativa" (ZILBERMAN, 1987, p. 21).

Sendo assim, elegemos como objetivo geral apresentar livros infantis que tratam sobre adoção e suas contribuições para a construção de uma cultura adotiva. Já os objetivos específicos consistem em refletir sobre a contribuição da literatura no desenvolvimento da criança de 0 a 10 anos; e analisar e sugerir livros de literatura infantil que contemplam a temática em questão.

Quanto à metodologia, optou-se pela pesquisa qualitativa, do tipo bibliográfica, e pela análise de livros infantis que trazem em seus enredos a adoção. Informa-se, ainda, que este artigo é fruto de um Trabalho de Conclusão de Curso vinculado aos projetos de pesquisa e extensão ${ }^{3}$, ambos da Universidade Estadual de Londrina.

A seguir, apresentaremos os resultados deste estudo. A saber, num primeiro momento, refletiremos sobre a importância da literatura no desenvolvimento infantil, com ênfase no uso do texto literário para introduzir diferentes assuntos na escola, como a adoção. Em seguida, foram eleitos oito livros de literatura infantil, analisando sua contribuição para a construção de uma cultura adotiva na escola.

\section{A criança, a escola e a literatura: Implicações para a formação do leitor crítico}

A partir da leitura de autores cujas pesquisas tratam sobre a Literatura Infantil, tais como Coelho (1991), Kaercher (2001), Fernandes (2009), Jacoby (2003), Batista (2007), Jorge (2003), entre outros, apresentaremos a seguir algumas questões sobre a relação entre a criança, o adulto (professores, pais e/ou responsáveis), a obra literária e a formação do leitor crítico.

\footnotetext{
${ }^{3}$ Projeto de Pesquisa - A cultura da adoção no contexto da Educação Infantil e dos anos iniciais do Ensino Fundamental: um estudo sobre concepções e práticas na organização do trabalho pedagógico. Projeto de Extensão - Adoção e acolhimento institucional: uma proposta de formação continuada para professores e gestores da Educação Infantil e do Ensino Fundamental I de Londrina e região.
} 
Coelho (1991) aponta que, por volta dos séculos IX e X, iniciou-se na Europa a transmissão oral de narrativas, como histórias populares, as quais são conhecidas como Literatura Folclórica. Algumas dessas histórias perpetuam até os dias de hoje. Já em meados do século XVIII, na Europa, teve início a Literatura Infantil, período em que a criança não era mais vista como um adulto em miniatura e passou a ser entendida como criança. Esse olhar diferenciado demonstrou as crianças como seres frágeis, mudanças foram realizadas na educação e assim foram surgindo contos e histórias específicas para esse público, bem como muitas obras adaptadas para crianças, como os contos de fadas dos Irmãos Grimm. Para a autora, no Brasil, José Monteiro Lobato é considerado o precursor da Literatura Infantil nacional, colocando-o como um divisor de águas, pois rompeu com raízes estereotipadas e trouxe novas ideias ao texto literário. Além disso, o autor deixou uma concepção utilitária e pedagogizante, deslocando-se para uma visão humanizadora.

Fernandes (2009) discute algumas especificidades da criança como leitora e a importância da literatura na formação e no desenvolvimento infantil. A autora demonstra como os que estão no convívio da criança e os que são responsáveis por sua formação - pais, professores, familiares etc. - representam diferentes perspectivas sobre a cultura familiar ou social, as quais estão enraizadas. Buscando trabalhar com as diferentes interpretações de mundo, a autora revela o uso da literatura e da fantasia, as quais são importantes para o desenvolvimento saudável do psiquismo infantil (FERNANDES, 2009).

Considerando a escola como um espaço privilegiado para o encontro do leitor e o livro, Coelho (1991) apresenta-a como o local em que sejam transmitidas as bases para a formação do indivíduo e, para isso, enfatiza a importância dos livros. Para ela, a literatura estimula o exercício da mente, a percepção do real em múltiplas significações, promove a consciência individual e sobre o outro. A autora ainda aponta a literatura como exercício de dinamização do estudo da língua, trazendo a cultura literária para a sala de aula, a criança se torna um aprendiz da cultura e da palavra 
empregada artisticamente, promovendo a criatividade diante do mundo, do ser humano e da vida.

Kaercher (2001) destaca a literatura como arte e fonte de prazer para a vida humana, sendo o fato de as crianças apreciarem narrativas, poemas e contos de fadas uma razão para trabalhar os livros e a leitura nas escolas. Assim, o papel do professor é o de mediar, despertando a curiosidade e atenção dos pequenos. Para a autora, é uma necessidade humana contar aquilo que vivemos e sentimos, e diante disso, "surgiu a literatura: do desejo de ouvir e contar para, através dessa prática, compartilhar" (KAERCHER, 2001, p. 81).

Diante da concepção interacionista da autora, é preciso considerar as interações da criança nos processos escolares, tanto com outras crianças quanto com os adultos que as cercam, e destes com a leitura. A interação poderá possibilitar a criança a construir, ouvir e entender diferentes questões e opiniões diante de uma mesma história, se colocando no lugar do outro e podendo conhecer diferentes realidades. Ou seja, as histórias literárias podem "auxiliar a criança a organizar suas experiências de vida, lidar com receios e alegrias, com conquistas e perdas, enfim, com sentimentos contraditórios" (KAERCHER, 2001, p. 85). Isso é relevante para o trabalho da escola em parceria com famílias de diferentes realidades e vivências, dentre elas, as adotivas.

Porém, Jacoby (2003, p. 184) afirma que "despertar o gosto pela leitura e fomentar a sua continuidade na adolescência e na vida adulta têm sido um desafio para os mais diversos setores interessados no tema". A autora, ainda, indica a necessidade do envolvimento da família no processo de leitura, pois com o apoio da família e o convívio com materiais de leitura desde a mais tenra idade haverá maior interesse do leitor. Por sua vez, a escola "se mantém como peça-chave da intermediação entre a literatura e o leitor, papel que lhe coube desde o momento em que se fez necessária como instituição educativa, responsável pela formação do infante, obviamente, vislumbrando o futuro adulto" (JACOBY, 2003, p. 185).

A autora faz uma breve comparação do uso dos meios eletrônicos na atualidade, apontando para a facilidade de acesso à interatividade que demanda a observação de imagens fragmentadas em uma tela, diante da leitura que envolve a concentração e 
esforço. Isso resulta em uma disputa do ato de ler com as redes sociais, televisão, vídeo games, entre outros. No mesmo sentido, a autora cita a concorrência entre as telas e os livros, mas defende que o prazer na leitura deve ser descoberto pelas crianças brasileiras para, assim, poderem desfrutar de um mundo no qual poderão se conhecer melhor e adquirir sabedoria.

Concordamos com Kaercher (2001, p. 83), que "[...] para formar crianças que gostem de ler e vejam na leitura e na literatura uma possibilidade de divertimento e aprendizagens precisamos ter, nós adultos, uma relação especial com a literatura e a leitura [...]". Nesse sentido, o desafio encontrado é ressignificar a leitura como uma atividade de prazer para o ser humano, de caráter fundamental diante da formação intelectual do leitor, visando descobertas, maior percepção, potencialização de áreas do cérebro em suas capacidades verbais e orais, testifica Jacoby (2003). Contudo, a autora acredita que as crianças apreciam e continuam gostando de uma boa história, que buscam possibilidades para aflorar sua criatividade e imaginação, e que a literatura traz um espaço para isso.

Sobre a hora do conto nas escolas, Batista (2007, p. 105) revela que "a história lida ou contada desempenha uma função catalisadora de interesse e prazer. Ora, se as crianças mobilizam-se é porque o mundo organizado em narrativa corresponde aos seus interesses e anseios e, por conseguinte, é significativo para elas". Dessa forma, existe uma identificação da criança nas histórias, uma experiência de o receptor encontrar semelhanças ou diferenças diante de um personagem. Ao realizar uma leitura, é possível 'vivenciar' realidades, sentimentos e momentos alternativos, o que multiplica as próprias experiências de mundo do leitor (BATISTA, 2007).

Fernandes (2009) destaca a importância do uso da linguagem simbólica para tratar de diferentes temas, hábitos e valores da sociedade, visando a emancipação do sujeito. Ao entender a trajetória de um personagem, é possível desencadear um efeito de reavaliação ou superação de dificuldades, por exemplo. Além disso, a criança poderá ter: auxílio na sua busca por maturidade psicológica e social; uma visão mais 
ampla das emoções e pensamentos; e estímulo para uma produção de linguagem mais elaborada.

Em conformidade com Candido (1989), é possível afirmar que a literatura é um direito básico, indispensável para a criança, e vista como necessidade universal. Entretanto, é possível perceber como esse direito acaba sendo negado, tanto pela falta de recursos e acesso aos livros quanto pela prática docente, que acaba desvalorizando o trabalho da literatura infantil. Portanto, cabe ao professor criar situações "[...] de leituras fundadas na liberdade de escolha e no ludismo, alicerçadas em bases teóricas sobre o gênero literário em questão, o processo de leitura, as características emocionais e cognitivas infantis e a metodologia de trabalho mais adequada" (AGUIAR, 2011, p. 8).

O papel do educador, nesse sentido, é proporcionar momentos de leitura intencional com a intenção de potencializar as funções psíquicas de seus alunos, utilizando estratégias para explorar sensações e significados. Para Fernandes (2009), o texto poético desenvolve no leitor a "[...] compreensão da linguagem como representação da experiência humana, estabelecendo uma ponte entre a criança e o mundo e fornecendo-lhe instrumentos eficientes para que ela conheça seu próprio universo interior e possa expressar-se [...]" (FERNANDES, 2009, p. 100).

A autora encoraja os educadores a explorar a musicalidade do poema, construir significações para a sonorização junto às crianças, criar exercícios de exploração das sensações, não visando somente a decodificação dos signos, mas uma participação que "busca na memória os conhecimentos arquivados e projeta sobre o texto, atuando na construção dos significados e dos sentidos possíveis" (FERNANDES, 2009, p. 103).

Sendo assim, a literatura infantil precisa tomar seu 'lugar' na garantia de uma possibilidade lúdica e literária no que tange ao processo de ensino e aprendizagem. Entretanto, o ensino da leitura e da "[...] literatura deve ser oportunizado desde a mais tenra idade, sem o objetivo de alfabetizar precocemente, mas de fazer com que as crianças explorem esses objetos de acordo com o seu período de desenvolvimento e se humanizem" (COSTA; GIROTTO, 2016, p. 33). As autoras destacam a importância do conhecimento sobre Literatura Infantil, em especial, no que se refere às escolhas de 
livros literários e às atitudes leitoras nos cursos de formação de professores, de modo que possam utilizar estratégias eficazes no processo de formação das crianças ao ler e contar histórias.

Enquanto narrativa literária, o professor precisa revelar o caráter artístico do texto, como destaca Batista (2007). Segundo a autora, a contação de histórias vem sendo aperfeiçoada com o passar do tempo, não deve ser uma improvisação somente para a transmissão da história, mas o contador deve estar familiarizado com a história e todos seus elementos. Isso possibilitará uma leitura com maior domínio do conteúdo, propiciando a atenção e a imaginação das crianças.

Batista (2007) traz em seu texto indicações para o professor diante do momento de contação de histórias, como a postura confortável, uma organização de modo que todos possam ver o contador e ideias para brincar com os livros (bingo, teatro, inventar outro final, desenhar, entre outros). Todavia, a preparação para uma sessão de contação de história deve ter cuidados, como a seleção da história, a programação do tempo, pausas e silêncios para fluir a imaginação, movimentos corporais, olhares e tons de voz que podem ser utilizados. Esse conjunto de fatores fará com que a história possa atrair seus ouvintes.

Sobre a criança, o prazer de ouvir e contar histórias, Jorge (2003) reconhece o ato de narrar como algo cultural, formando elos entre os diferentes tempos e mundos, possibilitando que os indivíduos conheçam melhor a si mesmo e o outro. A autora propõe, então, a 'roda de histórias". Para ela, a 'roda de histórias' é uma proposta e uma prática que avançam em relação à 'hora do conto', valorizando a memória coletiva e a experiência do grupo, garantindo aos narradores a possibilidade de expressão plena (JORGE, 2003, p. 100). Além disso, Jorge (2003, p. 100) lembra que “[...] na medida que cada participante é narrador, leitor e ouvinte, institui-se a dinâmica necessária para que todos possam se expressar e exercitar o compartilhamento".

Para a autora, o momento da leitura deve ser coletivo, não polarizado, e deve despontar o narrador dentro de cada um. A fala dos participantes deve ser livre, de modo a fluir a imaginação, na qual cada um encontra sua manifestação e expressão, 
favorecendo um processo de construção de sentidos. A 'roda de histórias' deve ser uma prática educacional que estimule a expressão cultural das crianças, trazendo o prazer de ler, ouvir e contar histórias. Tendo em vista a Educação Infantil, a autora propõe, de início, o uso de brincadeiras com palavras, como parlendas, trava-línguas, adivinhas, poesias, histórias lúdicas ou cantigas. Assim, a criança vai construindo a realidade e desvendando o mundo. Ela expõe que,

[...] apesar de a literatura ser uma complexa atividade de lidar com palavras, exigindo capacidades presentes de abstração, criança e literatura combinam muito bem, pois seu encontro realiza-se no âmbito do artístico, sensível, lúdico, enfim, do imaginário (JORGE, 2003, p. 114).

Sobre o papel do professor, a autora propõe a mediação entre a literatura e a criança, disponibilizando livros previamente selecionados, colaborando para o compromisso com a leitura, formando leitores críticos que refletem sobre o lido e estabelecem relação entre o que leram e suas experiências. "A literatura está aí, para ser lida. E, como leitora, para ser vivida. Cabe a cada um, a sua descoberta" (JORGE, 2003 , p. 123). Portanto, cabe ao professor "[...] ser delineador das pegadas iniciais que incentivarão a curiosidade das crianças, para segui-la, rumo ao mundo fantástico dos livros e das histórias" (JORGE, 2003, p. 123).

Arena (2010) compreende que o papel de mediação do professor no processo literário é imprescindível, planejando intervenções didáticas junto aos alunos. 0 contato da criança com a arte corrobora a possibilidade de compreensão e transformação da realidade, pois o processo educacional assume "função de formação integral do homem e de suas funções consideradas superiores e criativas em todas as áreas do conhecimento" (ARENA, 2010, p. 32). A leitura é um instrumento de desenvolvimento da mente humana, o que constitui o processo de humanização e progresso das funções psíquicas superiores, visando a apropriação da cultura (ARENA, 2010). Segundo Leontiev (1978), na medida em que nos apropriamos da cultura, nos 
tornamos mais humanos; dessa forma, a literatura possibilita a construção e o desenvolvimento cultural da criança.

Considerando, ainda, a importância da relação entre a escola e a família, cabe relatar a contribuição que a literatura pode trazer diante do desenvolvimento infantil. Coelho (1991) relata que o primeiro acesso de muitas crianças aos livros acontece dentro da escola, no âmbito da Educação Infantil, e já nesse momento de exploração, existe um estímulo da mente e da percepção de novas realidades, e abrange múltiplos níveis de observação e interação. O desenvolvimento no entendimento de emoções e sentimentos é concebido por meio da leitura de diferentes temáticas. Rodrigues (2005, p. 4) revela que:

\begin{abstract}
A contação de histórias é atividade própria de incentivo à imaginação e o trânsito entre o fictício e o real. Ao preparar uma história para ser contada, tomamos a experiência do narrador e de cada personagem como nossa e ampliamos nossa experiência vivencial por meio da narrativa do autor. Os fatos, as cenas e os contextos são do plano do imaginário, mas os sentimentos e as emoções transcendem a ficção e se materializam na vida real.
\end{abstract}

Dessa forma, não há dúvidas de que a leitura irá auxiliar e promover o desenvolvimento psíquico e cognitivo das crianças. Por isso, é extremamente importante que haja uma preparação dos professores para fazer uso dessa ferramenta. Isso possibilitará trabalhar as diferentes temáticas vivenciadas na atualidade, permitindo os pequenos a não apenas conhecer, mas entender novos sentimentos e emoções, por exemplo, aqueles relacionados à adoção.

Com um olhar voltado para a adoção, há a necessidade de o professor trabalhar a literatura infantil para contribuir no processo de compreensão dos conteúdos historicamente construídos em sintonia com as novas demandas contemporâneas em relação à diversidade familiar. $\mathrm{O}$ professor deve considerar a qualidade estética, o conhecimento prévio dos alunos e a seleção de obras literárias ricas em conteúdo, bem como promotoras da formação leitora e crítica do educando desde a mais tenra idade, no caso, na educação infantil. 
Adoção nos livros de literatura infantil: Uma possibilidade de trabalho na Educação Infantil e no Ensino Fundamental I

Bettellheim (1980) afirma que as histórias infantis acabam evitando temas considerados difíceis de trabalhar, como problemas existenciais, morte, envelhecimento, adoção, entre outros. Entretanto, isso acarreta em um comprometimento na formação das crianças, pois são essas questões que vão desenvolver sua capacidade de estarem preparadas para aquilo que poderão enfrentar ao longo da vida.

De acordo com Pantoja (2020), temas polêmicos como "a separação dos pais, a morte, o envelhecimento e outras questões controversas tardaram a ganhar as prateleiras infantis e permaneceram ainda por anos sob o esteio da esquivança" (PANTOJA, 2020, p. 903). Sobre a adoção, "somente na década de 1980 especialistas passam a identificar títulos literários destinados a crianças e que abordam 0 abrigamento, a institucionalização e a adoção" (SCHREINER, 2001 apud PANTOJA, 2020, p. 903).

A autora destaca o silenciamento social e, consequentemente, literário, em torno da adoção. Entretanto, temos avançado nesse sentido, hoje falamos de adoção com mais frequência, seja nos meios de comunicação, nos Grupos de Apoio à Adoção, na Literatura etc. Por outro lado, ainda hoje convivemos com o tabu, os mitos e preconceitos da adoção e, como resultado, a dificuldade dos professores de abordar tal temática na escola, uma vez que os cursos de formação inicial e continuada praticamente não contemplam o conteúdo 'adoção' em seus currículos (MORENO; BATISTA, 2017). Por essa razão, decidimos indicar aqui alguns títulos literários que trazem em primeiro e segundo foco a adoção, por acreditar que eles podem ser um veículo de comunicação, de informação sobre a constituição de famílias pela via adotiva.

Ao falar sobre adoção na escola, menciona que os professores precisam entender que pai e mãe são aqueles que exercem a maternidade e a paternidade: que cuidam, que acolhem, o que pode acontecer ou não com aquele que gestou, que gerou a 
criança. Logo, a adoção é uma forma de fazer-se pai, de 'paternar', de fazer-se mãe, de 'maternar', de tornar-se filho, diferente de gerar, de gestar. Corroboramos a ideia de que os filhos, inclusive os biológicos, precisam ser adotados pelos seus genitores, para que estes se tornem pais de fato, não apenas de nascimento (PROGRAMA..., 2016).

Uma vez compreendido os conceitos, o professor terá facilidade de entender que a família é o lugar do encontro afetivo, e não um produto biológico; logo, uma família homoafetiva é tão legítima quanto uma família heteroafetiva. Para tanto, é preciso haver uma ruptura com o conceito de que pai e mãe são aqueles que gestam. Gestação não depende da maternidade, pois para exercer a maternidade e a paternidade é preciso ir além do aspecto biológico, é preciso adotar, acolher, cuidar do nascituro, da criança e do adolescente (PROGRAMA..., 2016).

No que diz respeito à escolha dos livros sobre adoção, aqueles escritos por pais adotivos costumam não vincular qualquer tipo de conflito em relação ao tema. Já as obras que têm a adoção como foco secundário e os clássicos da literatura infantil como O patinho feio, Mogli, Cinderela, entre outros - compreendem inúmeras histórias de crianças que não são criadas por seus pais biológicos, representando situações de conflito (VIERA, 2006). Contudo, os livros de autoria de pais e mães adotivos podem aproximar o professor do universo da adoção, ajudando-o a falar sobre o assunto de forma simples e adequada à linguagem das crianças ${ }^{4}$.

As discussões feitas até aqui comprovam que existe um papel elementar da literatura na formação integral das crianças, que vai desde o desenvolvimento das funções psíquicas até a possibilidade do acesso à cultura. Desse modo, realizamos a seleção de oito livros infantis que serão aqui analisados e indicados como possibilidades lúdicas, literárias e de ensino na Educação Infantil e no Ensino Fundamental I.

\footnotetext{
${ }^{4}$ Exemplo disso é a explicação de que todas as crianças nascem de uma barriga - da sua mãe biológica e que, em casos de adoção, as mães adotivas procuram a Vara da Infância, esperam por seus filhos, até que o juiz entrega a criança para sua nova família.
} 
O primeiro livro é Somos um do outro: um livro sobre adoção e famílias, de Todd Parr, autor conhecido por abordar em suas obras questões relacionadas à família e valores. A obra trata o tema de maneira simples, levando ao leitor o entendimento de que existem muitas formas de se constituir uma família, sendo uma delas por meio da adoção. Muitos adultos (pais e professores) têm dificuldade de falar sobre adoção com as crianças, um tema complexo e até mesmo difícil de ser abordado de forma clara, honesta e natural. Em Somos um do outro, as ilustrações são grandes e coloridas, e as frases curtas direcionam o livro para o público infantil, possibilitando a criança fazer conexões de suas vivências ao texto literário, como no seguinte trecho: "Somos um do outro porque [...]. Você precisava de alguém para dizer 'Eu te amo'. E nós tínhamos amor para dar" (PARR, 2009, p. 28-29).

O livro 0 menino que não nasceu da barriga da mãe, de autoria de Carmem Lucia Eiterer, aborda de forma primária o tema adoção, pautando diferentes conceitos desse contexto. A história conta os dilemas de um garoto, seus medos diante do preconceito daqueles que estão à sua volta e de não ser aceito como filho de sua mãe adotiva. Entretanto, a trama mostra que não são os laços de sangue e semelhanças físicas que o fazem filho de sua mãe. O livro mostra que as mães se constituem de diferentes formas, e os nascimentos também podem acontecer de maneiras desiguais, como as borboletas e sapos que passam pela metamorfose, ou as mulheres que podem ter um problema de saúde que as impossibilita de engravidar; ou seja, diferentes motivos levam à adoção. Além disso, para se aproximar do público infantil, a autora usa vários exemplos com animais e objetos que estão no cotidiano das crianças (EITERER, 2011).

No livro Ganhei uma menina, de Tereza Yamashita e Luiz Brás (2012), conta-se a história de um cachorro, que tem como donos o casal Pedro e Paula. Então, esse casal adota uma filha, e o cachorro, em seu entendimento, acredita que ganhou essa menina de seus donos. Com humor, ele mostra como se comporta a menina, seus hábitos, como eles brincam, passeiam e tomam banho juntos. O diferencial é perceber, pela perspectiva do cão, como é divertido e emocionante ter um novo membro da família em casa. Dos 3 aos 7 anos, as crianças encontram-se na fase do pensamento lúdico; 
por essa razão, gostam bastante de histórias cujos personagens são animais que falam. Como a história do livro é narrada por um cão, as crianças gostam bastante.

A obra de Jamie Lee Curtis, Conta de novo: a história da noite em que eu nasci, valoriza o momento de contar a história da criança, de como ela foi concebida e de como chegou até seus pais. Na obra, a criança pede para os pais lhe contarem sua história, mas é possível perceber como ela mesma já conhece todos os detalhes desse dia e tudo o que aconteceu. Na adoção, é importante que não haja segredos sobre a história da criança: é preciso que ela conheça seu passado, sua própria história, para que ela construa sua identidade. No livro, a criança tem orgulho de ouvir e contar sua história, pois acredita que é uma história única, que narra a sua chegada na sua família e o dia em que conheceu seus pais (CURTIS, 2005).

As cenas mostram a alegria de seus pais ao encontrar e conhecer a bebê, como tiveram dificuldades de trocar a fralda, a felicidade de pegar a bebê tão desejada no colo. O livro revela, ainda, a árvore genealógica que a menina construiu diante de sua história. Nessa árvore genealógica, ela desenha a 'moça e moço que me fez' juntamente à linha dos pais, pois não pode ignorar o fato de sua origem (CURTIS, 2005). Essa história pode auxiliar muitas crianças a compreender que crianças adotadas possuem dois casais parentais, os genitores e os pais adotivos, sendo que os últimos não geram, mas exercem as funções materna e paterna; logo, são judicial e verdadeiramente pais e mães.

Sávio Bittencourt, em Nino e a casa dos Meninos Invisíveis, traz como foco o cotidiano de crianças que vivem em abrigos, abandonadas pela sociedade. A história começa com a apresentação de Nino, seus amigos e as configurações familiares encontradas na Rua Margarida, de como todos viviam felizes e tinham suas casas coloridas. Entretanto, existia uma casa na rua que não era colorida: era uma casa cinza, na qual viviam crianças sem pai, mãe ou família; seus rostos eram tristes e as pessoas não os viam, pois eram invisíveis (BITTENCOURT, 2014). O autor faz uma crítica à sociedade atual, pois muitas pessoas ignoram a existência dessas crianças, que se tornam invisíveis para aqueles que não têm um olhar para a adoção no Brasil. 
Infelizmente, por medida protetiva, muitas crianças são encaminhadas para as instituições de acolhimento e lá ficam em uma espera sem fim.

Voltando à história, Nino, com seu pincel mágico, ajuda a colorir a casa. O portão da casa começa a ficar aberto, os meninos deixam de ser invisíveis, e começam a brincar com a vizinhança da Rua Margarida. A sociedade, por sua vez, passa a enxergálos e conhecê-los, as crianças vão sendo adotadas por famílias e conseguem colorir suas vidas com amor (BITTENCOURT, 2014). A leitura desse livro contribui para a desconstrução de atitudes impensadas e preconceituosas. Ele mostra que o fato de as crianças e adolescentes estarem acolhidos não os torna diferentes, pois possuem os mesmos direitos de brincar, de ter amigos, de estudar, de serem cuidados, e o principal, de terem uma família.

Um gato chamado Peppo, escrito por Cleide Vitor Mussini Batista, conta a história de uma garotinha que adota o gato Peppo. O diferencial é que o pequeno gato é visto como desajeitado, de certa forma esquisito, e ninguém o quer. A história de Peppo começa com sua origem, a cidade em que nasceu, o nome dos seus pais, a perda deles, sua chegada no abrigo, os laços de amizade que fez lá, mas também o fato de que os outros gatos o excluíam, não gostavam dele. Chega um momento em que ele se pergunta o porquê de ser tão diferente (BATISTA, 2018).

Peppo é um gato autista. Mas, independentemente das diferenças, Peppo encontra uma menina que o escolhe, e ele pode explorar o mundo, brincar, conhecer coisas novas e também pode ter uma família por adoção. Dessa forma, a obra possibilita trabalhar a temática da adoção e das especificidades do autismo, da inclusão e da percepção de mundo diferente dos que apresentam essa condição.

Para trabalhar a adoção inter-racial e as diferenças físicas entre os pais e os filhos adotivos, escolhemos a obra Flávia e o bolo de chocolate, de Míriam Leitão (2015). A autora trabalha a temática, mostrando principalmente os preconceitos e dúvidas que podem surgir com o tempo quando se tem uma mãe branca e uma filha negra. Na história, a mãe de Flávia decide adotar uma criança, mas uma vizinha se mostra indignada com o fato de ela considerar a menina como filha, por elas serem muito diferentes. 
Em outro momento da história, Flávia se mostra infeliz por ter a pele marrom e sua mãe, branca, e toma a decisão de que não gosta de nada que é marrom. No decorrer da trama, a mãe utiliza diversas situações para demonstrar que as pessoas são diferentes, mas que isso não muda nada. Ela diz que todas são pessoas e que ela deve ter orgulho de quem ela é. A obra revela como é possível demonstrar para crianças como a cor da pele e as diferenças raciais não fazem das pessoas desiguais, cada um tem suas características e não é isso que determinará alguém ser filho ou não.

As obras apresentadas até aqui trazem a adoção em primeiro foco, alguns escritos por pais e mães adotivos; outros escritos por autores profissionais, simpatizantes da causa e pesquisadores sobre o tema. Para Pantoja (2020), a experiência individual não garante necessariamente "[...] a competência literária de conexão entre as múltiplas experiências familiares. Contar a sua história é diferente de contar histórias, por isso, o domínio autobiográfico cede certo espaço para o do escritor profissional, hábil em falar de si e do outro" (PANTOJA, 2020, p. 910).

A seguir, apresentaremos histórias que trazem a adoção como foco secundário. A vaca que botou um ovo, de Andy Cutbill, é uma dessas histórias apaixonantes. A vaca Mimosa acaba chocando um ovo de galinha, que é colocado escondido pelas galinhas para lhe dar um filhote. No decorrer da trama, é possível observar diferentes conflitos vindos da situação. Primeiramente, a reação das outras vacas ao receberem a notícia de que Mimosa havia botado um ovo. Existe o preconceito pela atitude da vaca de acolher um ovo, por ele ser diferente (CUTBILL, 2010).

Atitude adotiva é ter como seu um filho gerado por outro. "Na família adotiva acontece um fenômeno essencialmente amoroso, que é a filiação por afeto, na verdade, a única forma de filiação" (SCHETTINI, 2020, p. [1]). Por fim, ainda que sutil, a obra traz uma mensagem bastante apreciada no universo adotivo, ou seja, a maternidade não é apenas genética, ela é construída na relação, no vínculo que a vaca desenvolveu com o seu filhote de penas.

São muitos os títulos literários que trazem, de forma sutil e como foco secundário, a temática da adoção. Sendo assim, uma vez despertada no professor a 
importância de falar sobre o assunto desde a mais tenra idade da criança, a fim de construir na escola uma cultura adotiva, que consiste em "[...] respeitar as diferenças e singularidades do outro, a respeitar sua subjetividade e seu ser. [...]" (SCHETTINI, 2020, p. [1]), os docentes encontrarão na Literatura Infantil uma grande aliada.

Acreditamos que, por meio dos livros aqui apresentados, os professores da Educação Infantil e do Ensino Fundamental I, juntamente às famílias, poderão trabalhar a temática da adoção - que muitas vezes parece desafiadora - de forma lúdica e criativa, em seus mais diversos âmbitos e peculiaridades.

\section{Conclusão}

Diante da análise dos livros infantis, foi possível perceber a diversidade das temáticas contempladas nas obras, a adoção em si, as diferentes configurações familiares, os desafios da adoção, a vivência em abrigos, as diferenças físicas e culturais entre as famílias, entre outros. Tais temáticas podem ser abordadas de forma clara e acessível por meio da leitura nas salas de aula. Nesse sentido, a leitura é tida não apenas como um complemento, mas como uma ação em si, de reflexão, interpretação e visão diante de um assunto, podendo trazer novos questionamentos e problematizações.

Com base nas leituras e discussões realizadas, destaca-se a significativa contribuição da literatura infantil no desenvolvimento da criança, permitindo com que ela conheça novas emoções, sentimentos, palavras, despertando vivências novas, as quais desafiarão a criança em seu cognitivo e psíquico. Com isso, podemos concluir que os livros apresentados terão grande contribuição para que seja promovida a cultura da adoção nas escolas. Nesse contexto, as crianças terão maior entendimento da complexibilidade de sentimentos e emoções que envolvem a adoção, podendo contribuir ao levar suas ideias até seus contextos familiares e, assim, atingir a sociedade à sua volta.

Retomando a questão inicial deste artigo: os livros infantis que tratam sobre adoção contribuem para a construção de uma cultura adotiva? Concluímos que sim. A 
literatura infantil é um instrumento riquíssimo para a construção de uma cultura adotiva na escola; é uma linguagem capaz de aproximar a criança de diferentes temáticas, dentre elas, a parentalidade e a filiação adotiva. Por meio da Literatura Infantil, é possível que os professores da Educação Infantil e do Ensino Fundamental I trabalhem essa temática, colaborando para a construção da cultura da adoção na sociedade.

\section{Referências}

AGUIAR, Vera Teixeira de. Leitura literária para crianças brasileiras: das fontes às margens. In: SOUZA, Renata Junqueira de; FEBA, Berta Lúcia Tagliari (org.). Leitura literária na escola: reflexões e propostas na perspectiva do letramento. Campinas: Mercado de Letras, 2011. p. 7-11.

ARENA, Dagoberto Buim. A literatura infantil como produção cultural e como instrumento de iniciação da criança no mundo da cultura escrita. In: MENIN, Ana Maria da C. S.; GIROTTO, Cyntia Graziella G. S.; ARENA, Dagoberto Buim; SOUZA, Renata Junqueira de (org.). Ler e compreender: estratégias de leitura. Campinas: Mercado de Letras, 2010. p. 13-44.

BATISTA, Cleide Vitor Mussini. Hora do conto: um espaço para brincar com as palavras. In: PASCHOAL, Jaqueline Delgado (org.). Trabalho pedagógico na educação infantil. Londrina: Humanidades, 2007. p. 105-120.

BATISTA, Cleide Vitor Mussini. Um gato chamado Peppo. Londrina: Zeroseuns, 2018. $28 \mathrm{p}$.

BETTELHEIM, Bruno. A psicanálise dos contos de fadas. Tradução de Arlene Caetano. 11. ed. Rio de Janeiro: Paz e Terra, 1980. 335 p.

BITTENCOURT, Sávio. Nino e a casa dos meninos invisíveis. Rio de Janeiro: SRB Estudos, 2014. $36 \mathrm{p}$.

CANDIDO, Antonio. Direitos humanos e literatura. In: FESTER, A. C. Ribeiro (org.). Direitos Humanos e.... São Paulo: Brasiliense, 1989. p. 169-191.

COELHO, Nelly Novaes. Literatura Infantil: teoria, análise, didática. 7. ed. São Paulo: Moderna, 1991. 288 p. 
COSTA, Yngrid Karolline Mendonça; GIROTTO, Cyntia Graziella Guizelim Simões. Literatura infantil e formação de professores da infância. Educação em Análise, Londrina, v. 1, n. 2, p. 24-44, ago./dez. 2016. Disponível em:

http://www.uel.br/revistas/uel/index.php/educanalise/article/view/29133/21448. Acesso em: 27 abr. 2021.

CURTIS, Jamie Lee. Conta de novo: a história da noite em que eu nasci. Tradução de Clo Franklin. 2. ed. São Paulo: Moderna, 2005. 32 p.

CUTBILL, Andy. A vaca que botou um ovo. Tradução de Lenice Bueno. São Paulo: Moderna, 2010. 32 p.

EITERER, Carmem Lucia. O menino que não nasceu da barriga da mãe. Belo Horizonte: Mazza Edições, 2011. 32 p.

FERNANDES, Maria Lúcia Outeiro. O texto literário na formação da criança. In: ANGOTTI, Maristela (org.). Educação Infantil: da condição de direito à condição de qualidade no atendimento. Campinas: Alínea, 2009. p. 89-104.

JACOBY, Sissa. Criança e Literatura: mais livros, mais livres. In: JACOBY, Sissa (org.). A criança e a produção cultural: do brinquedo à literatura. Porto Alegre: Mercado Aberto, 2003. p. 183-208.

JORGE, Linice da Silva. Roda de histórias: a criança e o prazer de ler, ouvir e contar histórias. In: DIAS, Marina Célia Moraes; NICOLAU, Marieta Lúcia Machado (org.). Oficinas de sonho e realidade na formação do educador da infância. Campinas: Papirus, 2003. p. 95-111.

KAERCHER, Gládis Elise P. da Silva. E por falar em literatura... In: KAERCHER, Gládis Elise P. da Silva; CRAIDY, Maria (org.). Educação Infantil: pra que te quero?. Porto Alegre: Artmed Editora, 2001. p. 81-88.

LEITÃO, Míriam. Flávia e o bolo de chocolate. Rio de Janeiro: Rocco Pequenos Leitores, 2015. 36 p.

LEONTIEV, Alexis. O desenvolvimento do psiquismo. Lisboa: Livros Horizonte, 1978. 350 p.

MORENO, Gilmara Lupion; BATISTA, Cleide Vitor Mussini. Adoção, Educação Infantil e formação de professores: contextos, concepções e práticas. In: EDUCERE CONGRESSO NACIONAL DE EDUCAÇÃO, 13., 2017, Curitiba. Anais [...]. Curitiba: SIPD: CÁTEDRA UNESCO, 2017. p. 5343-5359. 
MORENO, Gilmara Lupion. Histórias infantis e adoção: por uma cultura adotiva na escola. In: JORNADA DE DIDÁTICA, 4., 2017, Londrina. Anais [...]. Londrina:

Universidade Estadual de Londrina, 2017. p. 388-396.

PANTOJA, Ana Claudia Freitas. Adoção em foco: tendências emergentes na literatura infantil contemporânea. In: CONGRESSO INTERNACIONAL DE LITERATURA INFANTIL E JUVENIL, 7, 2020, Presidente Prudente. Anais [...]. Presidente Prudente: Universidade Estadual Paulista, 2020. p. 903-914.

PARR, Todd. Somos um do outro: um livro sobre adoção e famílias. São Paulo: Panda Books, 2009. 32 p.

PROGRAMA Transversais - Guilherme Lima. Por Dilma Tavares Luciano. [Recife]: UFPE, 2016. 1 vídeo (20 min52). Disponível em:

https://www.youtube.com/watch?v=2aP5Don6Nt4. Acesso em: 26 abr. 2021.

RODRIGUES, Edvânia Braz Teixeira. Cultura, arte e contação de histórias. Goiânia: Editora Gwaya, 2005.

SCHETTINI, Suzana. Atitude adotiva. [Entrevista cedida a] Instituo Geração Amanhã. Instituo Geração Amanhã, [S. I.], 12 jun. 2020. Disponível em:

https://geracaoamanha.org.br/o-que-e-atitude-adotiva/. Acesso em: 09 fev. 2021.

VIEIRA, Joice Melo. Era uma vez... esta pode ser a sua história: a adoção em livros infantis. Cadernos Pagu, Campinas, v. 26, p. 59-85, jan./jun. 2006.

YAMASHITA, Tereza; BRÁS, Luiz. Ganhei uma menina. São Paulo: Scipione, 2012. $24 \mathrm{p}$.

ZILBERMAN, Regina. A criança, o livro e a escola. In: ZILBERMAN, Regina. A literatura infantil na escola. 6. ed. São Paulo: Global Editora, 1987. p. 11-32. 